\title{
Modification of Freezing Point for Hydrogel Extinguishant and Its Effect on Comprehensive Properties in Simulated Forest Fire Rescue
}

\author{
Ziwei Han ${ }^{1}$, Peiyao Chen ${ }^{2}$, Meifang Hou ${ }^{1, *}$, Qianqian Li ${ }^{3,4, *}$, Guijin Su ${ }^{3,4}$, Jing Meng ${ }^{3,4}$, Bin Shi ${ }^{3,4}$ \\ and Jie Deng ${ }^{2}$
}

check for updates

Citation: Han, Z.; Chen, P.; Hou, M.; Li, Q.; Su, G.; Meng, J.; Shi, B.; Deng, J. Modification of Freezing Point for Hydrogel Extinguishant and Its Effect on Comprehensive Properties in Simulated Forest Fire Rescue. Sustainability 2022, 14, 752. https:// doi.org/10.3390/su14020752

Academic Editor: António

Dinis Ferreira

Received: 4 December 2021

Accepted: 6 January 2022

Published: 11 January 2022

Publisher's Note: MDPI stays neutral with regard to jurisdictional claims in published maps and institutional affiliations.

Copyright: (C) 2022 by the authors. Licensee MDPI, Basel, Switzerland. This article is an open access article distributed under the terms and conditions of the Creative Commons Attribution (CC BY) license (https:// creativecommons.org/licenses/by/ $4.0 /)$.
1 College of Ecological Technology and Engineering, Shanghai Institute of Technology, Shanghai 201400, China; hanziwei2021@163.com

2 Tianjin Fire Research Institute of MEM, Tianjin 300381, China; chenpeiyao@tfri.com.cn (P.C.); djyi007@163.com (J.D.)

3 Key Laboratory of Environmental Nanotechnology and Health Effects, Research Center for Eco-Environmental Sciences, Chinese Academy of Sciences, Beijing 100085, China; gjsu@rcees.ac.cn (G.S.); jingm@rcees.ac.cn (J.M.); binshi@rcees.ac.cn (B.S.)

4 University of Chinese Academy of Sciences, Beijing 100049, China

* Correspondence: mfhou@sit.edu.cn (M.H.); qqli@rcees.ac.cn (Q.L.)

\begin{abstract}
Hydrogels, as an emerging extinguishant, exhibit outstanding performance in forest fire rescues. However, the near-zero freezing point limits their application at low temperatures. Herein, a sensible candidate commercial extinguishant was selected for analysis, and its freezing point was modified based on the evaluation of water absorption rate, agglomeration, viscosity, and water dispersibility. Notably, the introduction of different antifreeze and flame retardant exhibited a significant disparate impact on the viscosity representative factor. Ten orthogonal experiments were performed to optimize the specific formulation. When ethylene glycol, urea and ammonium bicarbonate, and xanthan gum were applied as antifreeze, flame retardant, and thickener, with the addition amounts of $5 \mathrm{~mL}, 0.08 \mathrm{~g}$ and $0.04 \mathrm{~g}$, and $0.12 \mathrm{~g}$, respectively, the hydrogel extinguishant with $1 \%$ ratio in $50 \mathrm{~mL}$ of ultra-water featured the remarkable performance. Compared with the original extinguishant, the freezing point of the modified sample decreased from -0.3 to $-9.2{ }^{\circ} \mathrm{C}$. The sample's viscosity was improved from 541 to $1938 \mathrm{cP}$, and the flame retardance time was more than $120 \mathrm{~s}$. The results of corrosion and biotoxicity show that the optimized hydrogel extinguishant satisfies the national standards. This understanding provides a deeper insight into the application of low-temperature extinguishants in forest fires.
\end{abstract}

Keywords: hydrogel extinguishant; modification; freezing point; formula optimization; environmentalfriendly

\section{Introduction}

Each year, several hundred thousand forest fires break out, destroying forest resources over a surface area of several million hectares around the world [1]. Forest fires in turn produce large amounts of $\mathrm{CO}_{2}$, which contributes to global warming [2]. Furthermore, the greenhouse effect has raised atmospheric temperatures, increasing the number of fires and burnt areas to a certain extent [3]. Forest fires in different areas have different characteristics. For example, during both periods from 1900 to 1934 and from 1988 to 2003 in the U.S. northern Rockies, regional-fire years were ones wherein warm springs were followed by warm, dry summers [4]. In contrast, several regions in China featured low rainfall, dry, and windy weather conditions. Thus, it should be noted that the fire season in southern and southwestern China is mainly in winter and spring [5]. Notably, the lower temperature in winter limits the potential for fire rescue. Therefore, the development and use of extinguishants is crucial for the control of forest fires at low temperatures. 
At present, the types of extinguishants vary and are still being updated, and many of them are not suitable for dealing with forest fires. Early measures to control forest fires mainly included spraying water over burning areas using a helicopter [6]. In Canada, planes can also drop thousands of liters of water on a fire every few minutes from a nearby lakes or rivers to fight fires [7]. The suppression effect of water on forest fires is not ideal, especially at the typical height of trees [8]. Besides, the extinguishants known as halons were also commonly used in the early days. However, they were gradually replaced due to their composition containing alkyl halides, which has been found to destroy the ozone layer $[9,10]$. Regarding other types of extinguishants, dry powder extinguishant features a poor cooling capacity for large combustible areas, which can easily cause reignition [11]. On the other hand, aerosol extinguishants are typically applied to indoor fire extinguishing and can generate high temperatures during use [12]. Water mist extinguishants were not persistent, which induced fires to easily rekindle after use $[13,14]$. The storage of an inert gas extinguishant requires excessive space and equipment, which is costly [15]. Foam extinguishants are expensive and have a short shelf-life duration [16,17]. Water-based extinguishants are relatively cheaper and have excellent fire extinguishing performance [18], but their long-term storage could potentially corrode metal containers. In addition, heavy metals are commonly added to water-based extinguishants as additives [19], which inevitably produce a toxic effect on the environment. Based on these disadvantages of current extinguishant types, it is imperative to exploit a lower-cost and more environmentally friendly extinguishant that can effectively target forest fires.

Hydrogels are a new type of extinguishant that exhibit excellent water retention capacity, greater heat capacity, and cooling ability [20]. Hydrogels are highly absorbent materials with a three-dimensional (3D) network structure. The unique structure can effectively enhance their water retention capacity and prevent the combustion of solid combustibles [21-23]. Thus, hydrogels greatly improve the shortcomings of low water adhesion and easy reignition after use. In the early days, hydrogel extinguishants were mainly used in coal mine fire prevention and control [24]. Li et al. [21] developed a novel hydrogel extinguishant with high water absorption and high resistance, which can effectively control coal mine fires. Later, they started to apply to buildings and forest fires. It is reported that hydrogel can reduce the amount of water used and significantly improve the efficiency of firefighting [25]. However, the freezing point of the hydrogel extinguishant on the market is generally close to $0^{\circ} \mathrm{C}$, which is not appropriate for use in cold conditions. Accordingly, developing an effective extinguishant with a low freezing point is of significant importance for the control of forest fires in cold seasons.

The most effective method to decrease the freezing point of solution is to add an antifreeze. If the glycol content of the drilling fluid is $60 \%$, the freezing point of the solution can reach $-50{ }^{\circ} \mathrm{C}$ at least [26]. However, the addition of certain additives may affect other properties of the extinguishant. Glycol is usually used as an antifreeze in sprinkler systems of large-scale rack-storage [27], but a high concentration addition can easily lead to the solution burning due to its flammability. As another additive, gellan gum is a common gel agent that can promote the formation of stable colloid solutions, but the water content of extinguishants first increases and then decreases with an increase in the content of the gellan gum [28]. Based on these studies, it can be concluded that extinguishant effectiveness is closely related to the type of additives and their proportions [29]. Notably, to improve the fire extinguishing performance, it has become common for flame retardants, stabilizers, thickeners, and other additives to be added [30]. However, to the best of our knowledge, there has been little research regarding the freezing point modification of extinguishants. Accordingly, the effect of freezing point modification on the other properties of extinguishants urgently needs further study.

This study aims to determine appropriate modifications for the hydrogel extinguishant currently on the market, so that it can be improved to exhibit excellent fire-fighting properties under low-temperature conditions, making it suitable for the effective control of forest fires. To achieve this, the physicochemical properties of commercial hydrogel 
extinguishants, including the dispersion property, water absorption rate, viscosity, and freezing point, were tested and compared. Then, a series of modification experiments were carried out based on the selected extinguishant with the best performance. Antifreeze, flame retardants, and thickeners were further added to extinguishants to optimize the base formulation. The effect of different types and proportions of additives on the performance of the extinguishant was investigated through an orthogonal experimental method. In addition, the corrosion and toxicity of the extinguishant after optimization were tested to evaluate the impact of the hydrogel extinguishant on the environment. This study could play a positive role in improving the efficiency of forest fire fighting and reducing casualties and economic losses.

\section{Materials and Methods}

\subsection{Chemicals}

Two hydrogel extinguishants, hereinafter referred to as extinguishants \#1 and \#2, were purchased from the extinguishant production factory, and the recommended ratio for both extinguishants was 0.5\%. For the flame retardants, APP was obtained from the Tianyao Chemical Industry (Yunnan, China), and urea, ammonium bicarbonate, and potassium acetate were supplied by Jiangtian Chemical Co. (Tianjin, China). Xanthan gum was obtained from Solaibao Technology Co. (Beijing, China), while lithium chloride and glycerol were acquired from Yuanli Chemical Co. (Tianjin, China), and ethylene glycol was purchased from Tianjin Jinke Reagent Co. (Tianjin, China). All reagents used in this experiment are analytically pure. Finally, ultrapure water was used in all of the experiments.

\subsection{Characterisation of Commercial Hydrogel Extinguishant}

The water absorption rate, particle size, freezing point, water dispersion, and viscosity of the \#1 and \#2 hydrogel extinguishant solutions were characterized. All experiments were performed in triplicate to ensure repeatability of the results, and the average values were used. The appropriate extinguishant was selected for the following performance optimization experiment.

\subsubsection{Particle Size Test and Water Absorption Rate Test}

The \#1 and \#2 extinguishant powders were evenly tiled onto the glass slides and observed under a digital microscope (M5000, EVOS, Waltham, MA, USA). Then, $1 \mathrm{~g}$ of powder was added to $1000 \mathrm{~mL}$ of ultrapure water. After soaking for an interval of $10 \mathrm{~s}$, the solution was filtered through a 300-mesh sieve, and the mass of the remaining gel on the sieve was weighed. The absorption rate was calculated using Equation (1):

$$
\mathrm{Q}=(\mathrm{Wt}-\mathrm{W} 1) / \mathrm{Wt}(\mathrm{Q} \text { unit }: \mathrm{g} / \mathrm{g}, \mathrm{Wt} \text {, and } \mathrm{W} 1 \text { unit }: \mathrm{g})
$$

where $\mathrm{Q}$ is the absorption rate, $\mathrm{Wt}$ is the mass of the powder after absorbed water, and W1 is the original mass of the powder. The water absorption rate at a specific moment was then calculated. The shortest time for the water absorption rate to reach equilibrium was recorded as the water absorption equilibrium time.

\subsubsection{Water Dispersion Test}

A certain amount of extinguishant powder was added to the ultrapure water to prepare a standard hydrogel solution with concentrations of $0.5 \%$ and $1 \%$. After $10 \mathrm{~min}$, the degree of flocculation of the powder was observed to reflect its water dispersibility.

\subsubsection{Viscosity Test}

The temperature of the electro-thermostatic water bath (DF-101S, YUHUA, Shanghai, China) was maintained at $26^{\circ} \mathrm{C}$. Appropriate rotors and speeds were selected to match the samples. A rotary viscosimeter (DV1, BROOKFIELD, Middleboro, MA, USA) was used to measure the viscosity of each sample. 


\subsubsection{Freezing Point Test}

The freezing point test was carried out in reference to the national standard GB (15308) [31]. For this test, the temperature of the freezing point meter (KD-T002, CADONHKHAICR, Beijing, China) was set at $-25^{\circ} \mathrm{C}$. The depth of the tubes containing the samples in the cold trap was not less than $100 \mathrm{~mm}$. The flow of the samples was observed after the temperature of the samples dropped to $0{ }^{\circ} \mathrm{C}$. The samples were taken out at every $1{ }^{\circ} \mathrm{C}$-drop in temperature to determine their fluidity. No flow occurred after the tubes containing samples were held horizontally for $5 \mathrm{~s}$, and the temperature at that moment was recorded as the freezing point.

\subsection{Modification of Hydrogel Extinguishant}

Effects of Various Additives on Properties of the Hydrogel Extinguishant

To test the effect of antifreeze on the performance of the extinguishant, $5 \mathrm{~mL}$ of potassium acetate, lithium chloride, ethylene glycol, and glycerol were added separately to four samples of $95 \mathrm{~mL}$ standard \#1 hydrogel extinguishant solutions $(0.5 \%)$. To explore the influence of flame retardants on the performance of the extinguishant, $2 \mathrm{~g}$ APP, $2 \mathrm{~g}$ urea, and $1 \mathrm{~g}$ ammonium bicarbonate were added into the $45 \mathrm{~mL}$ of standard hydrogel solution $(0.5 \%)$. After adding the additives, the viscosity and freezing point of the samples were tested using methods at Sections 2.2.3 and 2.2.4. To modify the selected extinguishant and determine the best material ratio, the hydrogel extinguishant powder, antifreeze, flame retardants, and thickener were added to $50 \mathrm{~mL}$ of ultrapure water in sequence. Then, the viscosity, freezing point, adhesion, and flame-retardant ability of each sample were recorded.

\subsection{Evaluation of Modified Hydrogel Extinguishant}

Adhesion and Flame Retardant Performance Tests of the Modified Hydrogel Extinguishant

This experiment simulated the adhesion of a hydrogel extinguishant solution on a wood surface and its resistance to flame. The experimental method of adhesion performance was as follows: wood strips with dimensions of $40 \times 40 \times 150 \mathrm{~mm}$ were selected and weighed. Five grams of each sample were evenly coated on the rectangular section of the wood strips. After being set at a $45^{\circ}$ incline for $20 \mathrm{~min}$, the wood strips after the static were weighed, and the residual mass of the samples on the surface of the wood strips was calculated, as shown in Equation (2):

$$
\Delta \mathrm{M}=\mathrm{M} 2-\mathrm{M} 1 \text { (M units : } \mathrm{g})
$$

where M1 and M2 are the masses of the original wood strips and the wood strips after tilting for $20 \mathrm{~min}$, respectively. The flame retardant experimental in this paper refers to the test method of GB 12441-2018 (Decorative Fireproof Coating) [32]. The strips were then situated horizontally and subjected to a flame-thrower with a central flame temperature of $\sim 1300{ }^{\circ} \mathrm{C}$ to burn the surface coated with samples at a distance of $6 \mathrm{~cm}$ until a blackened spot of $10 \mathrm{~mm}$ in diameter appeared on the wood surface, and the burning time was recorded. Untreated wood strips were set as blank control group.

\section{Results and Discussion}

\subsection{Characterisation of Commercial Hydrogel Extinguishant}

\subsubsection{Particle Size and Water Absorption Rate of \#1 and \#2 Extinguishants}

It is known that the water absorption rate of hydrogel extinguishant powder is related to its structure and particle size, which is an important index for measuring the performance of water absorption and water retention. As shown in Figure 1, the particle size of powder \#1 was mainly concentrated in the range of 50-150 $\mu \mathrm{m}$, which was smaller than that of powder \#2, 150-250 $\mu \mathrm{m}$. It is thought that a smaller particle size exhibits some excellent surface properties, such as a large specific surface area or high chemical activity, which can help the particles diffused more widely to some extent $[29,33]$. Also, smaller particle sizes can help the extinguishant absorb water faster and exhibit less agglomeration under the 
same time conditions. Since the action mechanism of hydrogel extinguishant mainly relies on its own unique structure to quickly absorb and keep a large amount of water attached to the surface of the object, so water absorption rate and the time to reach equilibrium are important indicators to judge the performance of hydrogel extinguishant [22]. Figure 2 presents the water absorption rates of the two hydrogel extinguishant powders. The water absorption rate of powder \#1 was faster at first, within 0-30 s, and then gradually slowed down until balance was achieved at $50 \mathrm{~s}$. The water absorption rate was $260 \mathrm{~g} / \mathrm{g}$. For powder \#2, the speed of water absorption was relatively stable within 0-50 s. Its balance absorption was obtained at $60 \mathrm{~s}$, which was slower than that of powder \#1. In contrast, its water absorption rate was lower at $230 \mathrm{~g} / \mathrm{g}$. This result indicates that powder \#1 had a better water absorption capability.

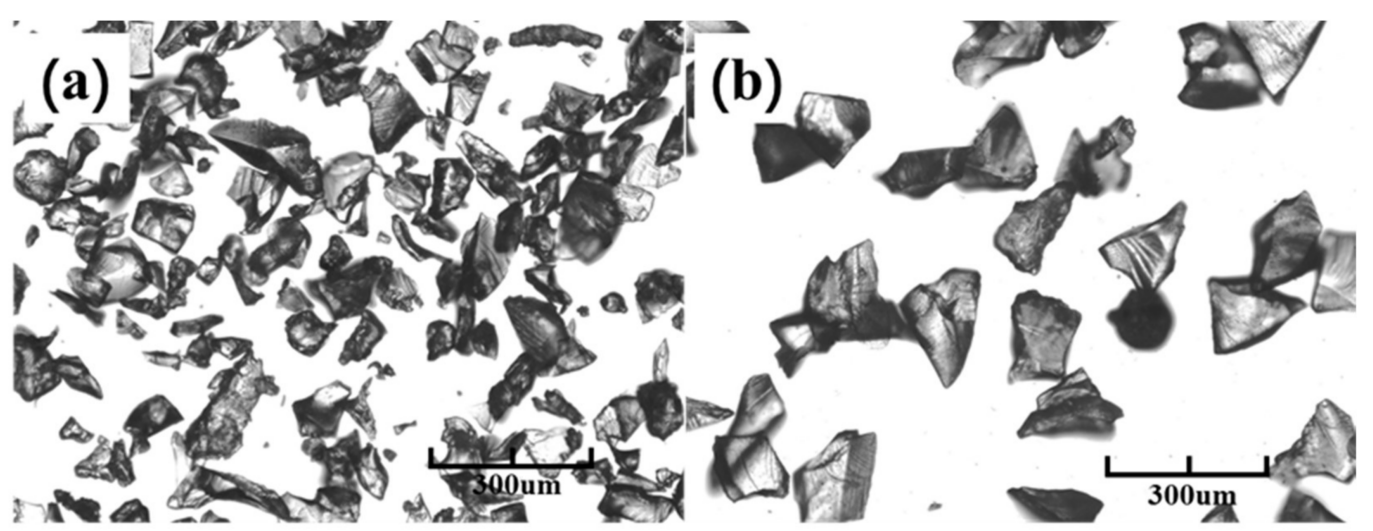

Figure 1. Microscope image of (a) \#1 and (b) \#2 hydrogel extinguishant powders.

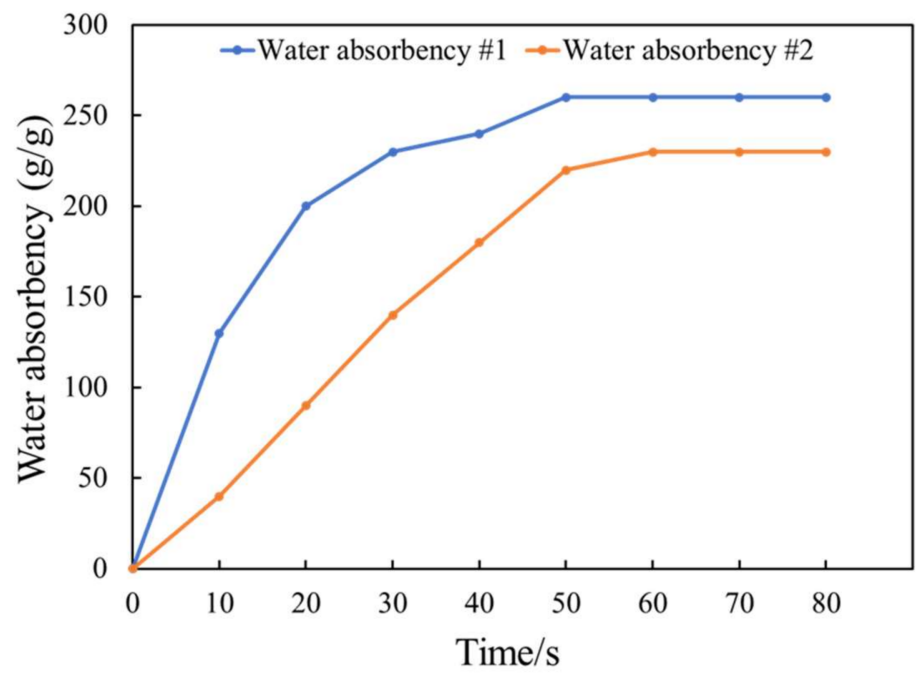

Figure 2. Water absorption rate of \#1 and \#2 hydrogel extinguishant powders.

\subsubsection{Freezing Point and Viscosity of \#1 and \#2 Extinguishants}

The freezing point of the extinguishants determines the lowest temperature at which they can work properly. As depicted in Table 1, the freezing points of hydrogel solutions \#1 and \#2 were $-0.3^{\circ} \mathrm{C}$ and $-0.5^{\circ} \mathrm{C}$, respectively, which did not change with the concentration of the hydrogel solution. Viscosity, as a physical property that measures the glutinousness and fluidity of a fluid, was also considered. Fluids with low viscosity have good fluidity and less adhesion to objects. Increasing the viscosity of the fluid could facilitate its attachment, whereas a decrease in its fluidity is not conducive to ejection from the device. Therefore, to effectively control forest fires, it is critical to choose the appropriate viscosity based on the nature of the hydrogel extinguishant itself. The viscosity of hydrogel solution \#1 was 33.6\% and $30.8 \%$ higher than that of hydrogel solution \#2 at the two concentrations, respectively. 
The viscosity of the samples increased with the addition of the two extinguishant powders. By comparison, the viscosity of hydrogel solution \#1 was higher than that of solution \#2 and modest at $0.5 \%$ concentration. Notably, the freezing points of the two extinguishants were close, while neither of these two extinguishants were suitable for the cold conditions.

Table 1. The freezing point of the experimental hydrogel solutions \#1 and \#2.

\begin{tabular}{ccc}
\hline Material & Freezing Point $\left({ }^{\circ} \mathbf{C}\right)$ & Voscosity $(\mathbf{c P})$ \\
\hline $0.5 \%$ solution \#1 & -0.3 & 541 \\
$1.0 \%$ solution \#1 & -0.3 & 4386 \\
$0.5 \%$ solution \#2 & -0.5 & 405 \\
$1.0 \%$ solution \#2 & -0.5 & 3354 \\
\hline
\end{tabular}

\subsubsection{Water Dispersion of \#1 and \#2 Extinguishants}

Water dispersibility determines whether the extinguishant powder can form a stable and effective solution in water, and is typically determined by the degree of flocculation of the powder. As shown in Figure 3, both $0.5 \%$ and $1.0 \%$ concentrations of hydrogel solution \#1 were uniform gels and had no obvious power flocculation. Nevertheless, significant powder flocculation was observed at $0.5 \%$ and $1.0 \%$ concentrations of hydrogel solution \#2. In addition, hydrogel solutions \#1 and \#2 could both flow easily when they were placed at an inclination of $45^{\circ}$ at a concentration of $0.5 \%$. However, when the added amount of the two extinguishant agents was doubled, the viscosity of the formed hydrogel solutions increased by approximately 8 times and hardly flowed (Table 1 and Figure 3 ). This suggests that solution \#1, with a powder concentration of $0.5 \%$, had a better water dispersion performance, which could facilitate the addition of various additives to form a more uniform solution. Accordingly, based on the aforementioned results, the smaller particle size helps absorb water faster and less agglomeration. Extinguishant \#1 showed a better water absorption rate, less agglomeration, and had appropriate viscosity and water dispersibility. Thus, it is a sensible candidate for improving the freezing point and other properties.

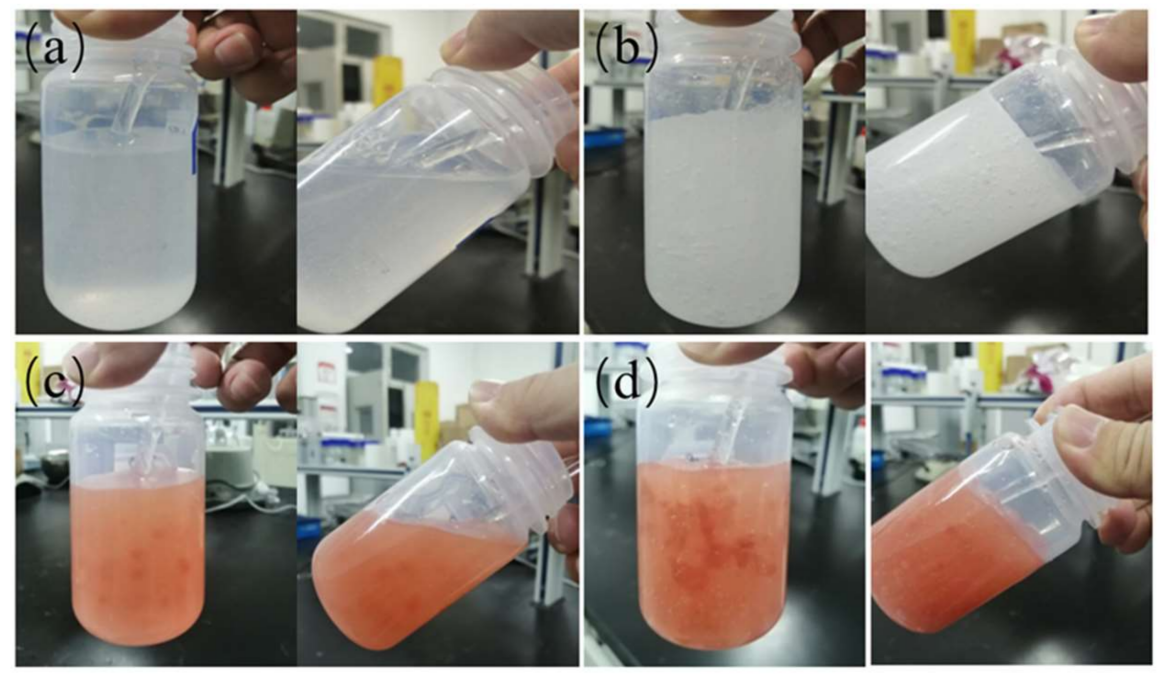

Figure 3. Different concentrations of hydrogel sample dispersion status: (a) $0.5 \%$ and (b) $1.0 \%$ concentration of hydrogel extinguishant solution \#1; (c) $0.5 \%$ and (d) $1.0 \%$ concentration of hydrogel extinguishant solution \#2.

\subsection{Effect of Freezing Point and Flame Retardant Performance Modifications on Viscosity of \#1 Extinguishant}

As mentioned above, the addition of antifreeze and other additives may change the performance of the extinguishant. Of the related performance indicators, viscosity is 
considered the main indicator for evaluating fire extinguishing ability. Accordingly, the viscosity of the hydrogel extinguishant solution was chosen to preliminarily explore the effects of antifreeze and flame retardants. Inorganic salts and polyols are the main types of antifreeze that can significantly reduce freezing points [26,34]. Extinguishant \#1 performed best in the previous experiments. Therefore, four group extinguishant \#1 were used to test the influence of potassium acetate, lithium chloride, ethylene glycol, and glycerol on the viscosity of the hydrogel solution. According to result in Table 2, the viscosity of hydrogel solution decreased from $541 \mathrm{cP}$ to 9.6 and $10.2 \mathrm{cP}$, respectively, after adding potassium acetate and lithium chloride. This might be attributed to the significant destruction of the hydrogen bond network formed between the hydrogel extinguishant and water by the inorganic salts. In contrast, the viscosity of the hydrogel solution markedly increased from $541 \mathrm{cP}$ to 8310 and $7985 \mathrm{cP}$, respectively, after the addition of ethylene glycol and glycerol. This indicates that the addition of polyol-type antifreeze effectively improved the viscosity of the hydrogel extinguishant solution. We consider that the hydroxyl in polyols is a good hydrogen bond receptor and donor, working in synergy with the extinguishant to build solid hydrogen bond network. Accordingly, ethylene glycol was the preferred antifreeze selected from our study.

Table 2. Viscosity of hydrogel extinguishant solution \#1 after the addition of additives.

\begin{tabular}{|c|c|c|c|c|}
\hline & Type & Additives & $\begin{array}{c}\text { Concentration } \\
(\%)\end{array}$ & $\begin{array}{c}\text { Viscosity } \\
\text { (cP) }\end{array}$ \\
\hline \multirow{7}{*}{$\begin{array}{c}\text { Extinguishant \#1 } \\
(0.5 \%)\end{array}$} & - & - & - & 541 \\
\hline & \multirow{4}{*}{ Antifreeze } & Potassium acetate & $5.0 \%$ & 9.6 \\
\hline & & Lithium chloride & $5.0 \%$ & 10.2 \\
\hline & & Ethylene glycol & $5.0 \%$ & 8310 \\
\hline & & Glycerol & $5.0 \%$ & 7985 \\
\hline & $\begin{array}{l}\text { Flame } \\
\text { retardants }\end{array}$ & $\begin{array}{l}\text { APP, urea, ammonium } \\
\text { bicarbonate }\end{array}$ & $10 \%$ & 13.2 \\
\hline & Thickener & Xanthan gum & $2 \%$ & 80.4 \\
\hline
\end{tabular}

It has been reported that nitrogenous flame retardants and phosphonium flame retardants can synergistically enhance the flame retardant effect [35]. The flame retardant mechanism of APP is that after heat dehydration, APP is decomposed to polyphosphoric acid, facilitating the dehydration carbide of organic matter surface. Additionally, the nonvolatile phosphorus oxide and polyphosphoric acid could cover the surface of objects and cut off air to achieve the purpose of flame retardant [36]. In addition, urea and ammonium bicarbonate release non-combustible gas when heated, blocking the supply of oxygen. Therefore, in addition to antifreeze, the influence of three common flame retardants, APP, urea, and ammonium bicarbonate, on the viscosity of extinguishant was also investigated in this study. After addition of the three retardants into one set of 1\# extinguishant solution, the viscosity of the hydrogel solution significantly reduced from $541 \mathrm{cP}$ to $13.2 \mathrm{cP}$. Since low viscosity of the hydrogel solutions can weaken the adhesion and extinguishing effects, several substances should be added to improve the viscosity of the hydrogel extinguishant. The non-covalent bond (mainly hydrogen bond) between the side chain and main chain of xanthan gum can stabilize the whole structure [37]. Xanthan gum has a network structure in aqueous solution, which can limit the fluidity of water, so it has good thickening performance. For this, the common thickener xanthan gum was selected for its unique rheological properties and compatibility. After adding $0.1 \mathrm{~g}$ of xanthan gum, the viscosity of the hydrogel solution increased from $13.2 \mathrm{cP}$ to $80.4 \mathrm{cP}$. Therefore, the viscosity of the hydrogel solution was effectively adjusted by adding xanthan gum. 


\subsection{Formulation Optimisation of Various Additives}

Based on the results in Section 3.2, the improvement of individual property for extinguishants might have a negative impact on its nature. More importantly, it has been reported that the ratio of different additives also has a significant effect on the performance of extinguishants [27]. Therefore, extinguishant \#1 was modified to balance each performance. The order of different additives added into the solution was shown in Figure 4. Firstly, a certain amount of xanthan gum, then APP, urea and ammonium bicarbonate, ethylene glycol. Finally, powder \#1 was combined with the solution. To further optimize the amounts of various additives, single-factor experiments with ten groups were designed, and the results are listed in Table 3.

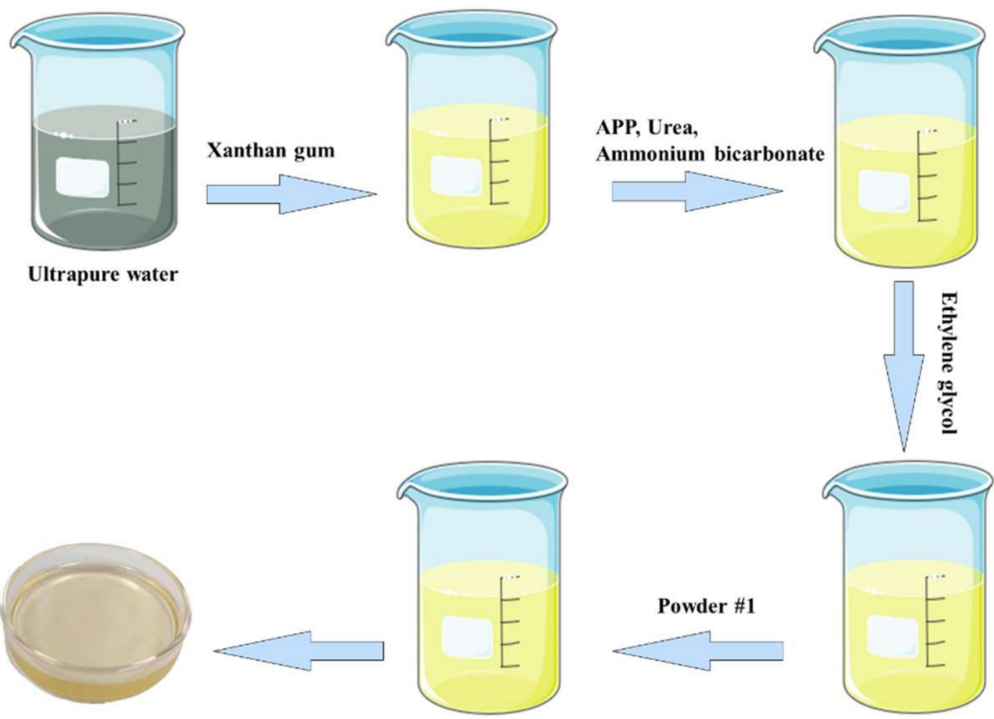

Figure 4. The order in which different additives were added to the solution.

Table 3. Single factor experiment of the modified hydrogel extinguishant formulation.

\begin{tabular}{cccccccc}
\hline Sample & $\begin{array}{c}\text { Ultrapure } \\
\text { Water }(\mathbf{m L})\end{array}$ & APP (g) & Urea (g) & $\begin{array}{c}\text { Ammonium } \\
\text { Bicarbonate (g) }\end{array}$ & $\begin{array}{c}\text { Xanthan } \\
\text { Gum } \mathbf{( g )}\end{array}$ & $\begin{array}{c}\text { Ethylene } \\
\text { Glycol (mL) }\end{array}$ & $\begin{array}{c}\text { Extinguishant } \\
\text { Powder \#1 (g) }\end{array}$ \\
\hline No. 1 & 50 & 0.08 & 0.08 & 0.04 & 0.04 & 5 & 0.5 \\
No. 2 & 50 & 0.08 & 0.08 & 0.04 & 0.04 & 5 & 0.35 \\
No. 3 & 50 & 0.08 & 0.08 & 0.04 & 0.04 & 5 & 0.2 \\
No. 4 & 50 & 0.08 & 0.08 & 0.04 & 0.04 & 5 & 0.5 \\
No. 5 & 50 & 0.08 & 0.08 & 0.04 & 0.08 & 5 & 0.5 \\
No. 6 & 50 & 0.08 & 0.08 & 0.04 & 0.12 & 5 & 0.5 \\
No. 7 & 50 & 0.08 & 0.08 & 0.04 & 0.12 & 5 & 0.5 \\
No. 8 & 50 & 0.08 & 0 & 0.04 & 0.12 & 5 & 0.5 \\
No. 9 & 50 & 0 & 0.08 & 0.04 & 0 & & 0.5 \\
No. 10 & 50 & 0.08 & 0.08 & &
\end{tabular}

Notably, Figure 5 presented the test process of adhesion and flame retardant performance of each group. In addition, the time from the beginning of the flame retardant test to the appearance of distinct black spots on the wood was recorded and used as an index to evaluate the flame resistance performance. In order to intuitively compare the degree of performance improvement of different samples, the adhesion and flame retardant performance of the control group with pure wood strip and the wood strip coated $0.5 \%$ concentration of 1\# extinguishant solution were measured, as shown in Table S1. The blank control group featured the shorter fire-retarding time with $4.3 \mathrm{~s}$. Figure 6 depicted the results of freezing point and viscosity, as well as adhesion and flame retardant performance of ten modified samples, respectively. Based on the results of No. 1, No. 2, No. 3, 
it can be found that the content of extinguishant had no obvious effect on freezing point. While viscosity, the residual mass on the wood strips and flame retardant performance of hydrogel extinguishant were enhanced with the increase of its powder content from $0.2 \mathrm{~g}$ to $0.5 \mathrm{~g}$. Thus, the appropriate powder content of the extinguishant was set to $0.5 \mathrm{~g}$. Whereafter, the doped amount of antifreeze could be identified according to the results of the No. 1, No. 4, and No. 5 samples. Results indicated that the freezing point of the samples decreased with the increase of ethylene glycol content. When the addition of ethylene glycol was $7 \mathrm{~mL}$, the freezing point of No. 5 was the lowest of the 10 samples with $-12.6^{\circ} \mathrm{C}$. Nevertheless, its flame retardant time decreased from $58.7 \mathrm{~s}$ to $44.5 \mathrm{~s}$ when compared with No. 4 sample. The viscosity and residual quantity of these three groups were comparable and undesirable. The results show that adding ethylene glycol can reduce freezing point and flame retardancy. After a comprehensive comparison, the best content of ethylene glycol is $5 \mathrm{~mL}$. Then, the dosage of xanthan gum was optimized, as shown in No. 1, No. 6, and No. 7 in Table 3. According to the test results in Figure 6, there is no obvious change in freezing point and residual quantity of these three groups. Comparatively, the viscosity was elevated from $361 \mathrm{cP}$ to $677 \mathrm{cP}$ when the addition of xanthan gum increased from $0.04 \mathrm{~g}$ to $0.12 \mathrm{~g}$. Meanwhile, the flame retardant time also increased from $46.0 \mathrm{~s}$ to $51.7 \mathrm{~s}$. Xanthan gum can effectively improve the viscosity and enhance the burning resistance. Thus, the doping amount of xanthan gum was set as $0.12 \mathrm{~g}$. To further extend the flame retardant time, the different combinations between various agents were experimented, being marked as samples No. 7, No. 8, No. 9, and No. 10, respectively. Based on their performance on various tests in Figure 6, it could be noted that the freezing points of the four groups of samples are relatively close, within the range of $-8.7^{\circ} \mathrm{C}$ and $-9.4^{\circ} \mathrm{C}$. The performance is not optimal when all three flame retardants were added (APP, urea and ammonium bicarbonate). Notably, when $0.08 \mathrm{~g}$ urea and $0.04 \mathrm{~g}$ ammonium bicarbonate were combined, No. 9 had the best all-around performance. Compared with the original \#1 extinguishant (Table S1), the freezing point of No. 9 decreased from $-0.3{ }^{\circ} \mathrm{C}$ to $-9.2{ }^{\circ} \mathrm{C}$, which can cope with forest fires in most cold areas. The viscosity of No. 9 reached up to $1938 \mathrm{cP}$ and the fire-retarding time was increased from $42.8 \mathrm{~s}$ to $121.8 \mathrm{~s}$. The adhesion mass on the wood surface was raised from $3.15 \mathrm{~g}$ to $4.8 \mathrm{~g}$ and the hydrogel solution applied to No. 9 almost entirely adhered to the woodblock (Figure 5). Therefore, urea and ammonium bicarbonate were selected as the flame retardant combination in this study. The comprehensive performance of the optimized hydrogel extinguishant is significantly improved compared with the original \#1 extinguishant.

\subsection{Safety Performance Evaluation of Modified Hydrogel Extinguishant}

The storage and transportation equipment of the extinguishants are mainly com-posed of metals. It is known that some additives may cause corrosion in storage and delivery devices. Hence, corrosion is an important index for evaluating the safety performance of extinguishants. In this study, the safety test referred to the national standard (GB 15308) was conducted [31]. Four pieces of steel sheet (Q235 steel) and aluminum sheet (LF21 aluminum) were chosen and weighed. After removing the oxide film, the surface area was calculated. Then, the metal sheets were placed into two conical flasks containing the modified No. 9 solution and the original 1\# hydrogel extinguishant solution, as shown in Figure $7 \mathrm{a}, \mathrm{b}$. The conical flasks were placed in a drying oven for 21 days. The mass of each metal sheet was weighed after removing the surface corrosion products. The degree of corrosion was calculated according to the formula in Equation (3):

$$
\mathrm{C}=1000 \times(\mathrm{m} 1-\mathrm{m} 2) /(21 \times \mathrm{A})
$$

where $\mathrm{C}$ is the corrosion rate, $\mathrm{mg} /\left(\mathrm{d} \cdot \mathrm{dm}^{2}\right), \mathrm{m} 1$ is the original mass of each metal sheet $(\mathrm{g})$, $\mathrm{m} 2$ is the mass of each metal sheet after being soaked in the sample (g), and A is the surface area of each metal sheet $\left(\mathrm{dm}^{2}\right)$. 

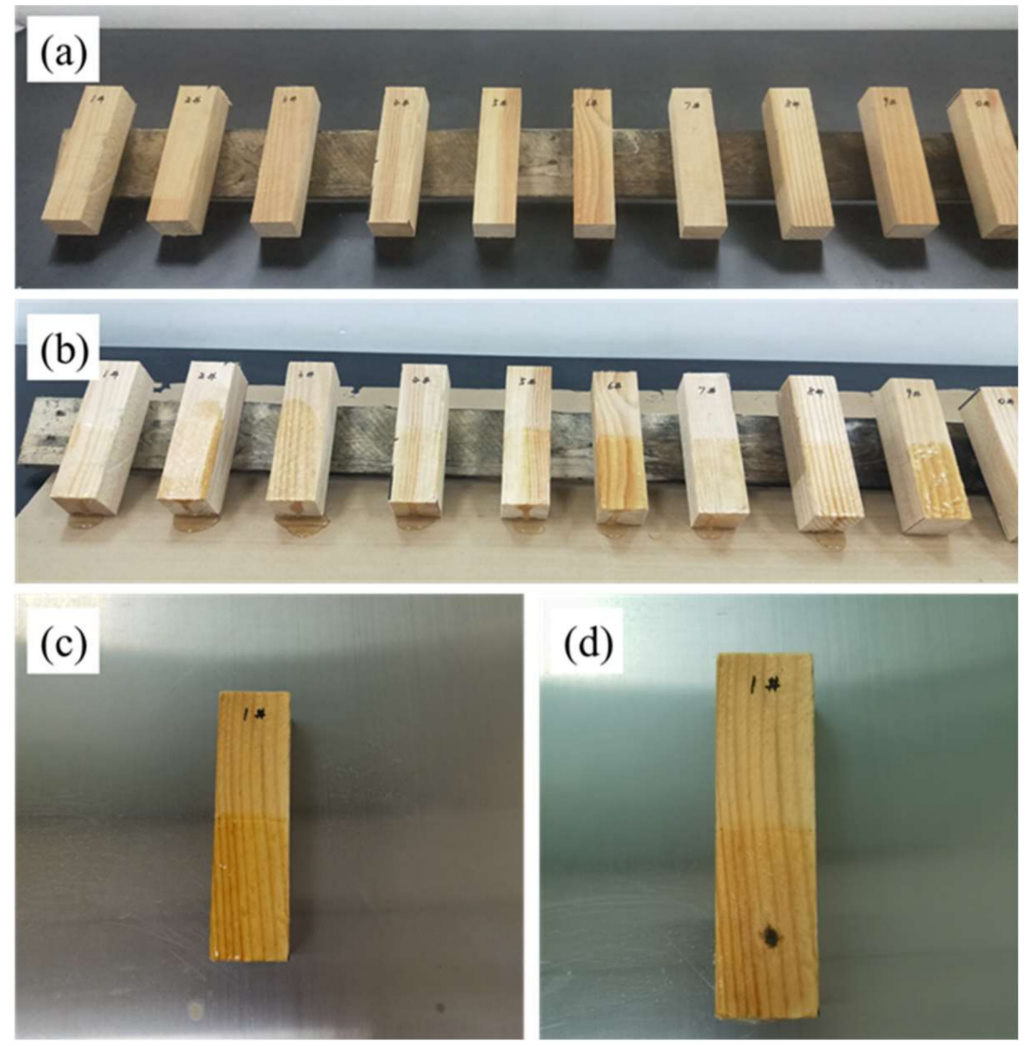

Figure 5. (a) Original wood strips and (b) wood strips after adhesion test. (c) Wood strip at the beginning of the flame retardant test and (d) state of wood strip after completion of flame retardant test.
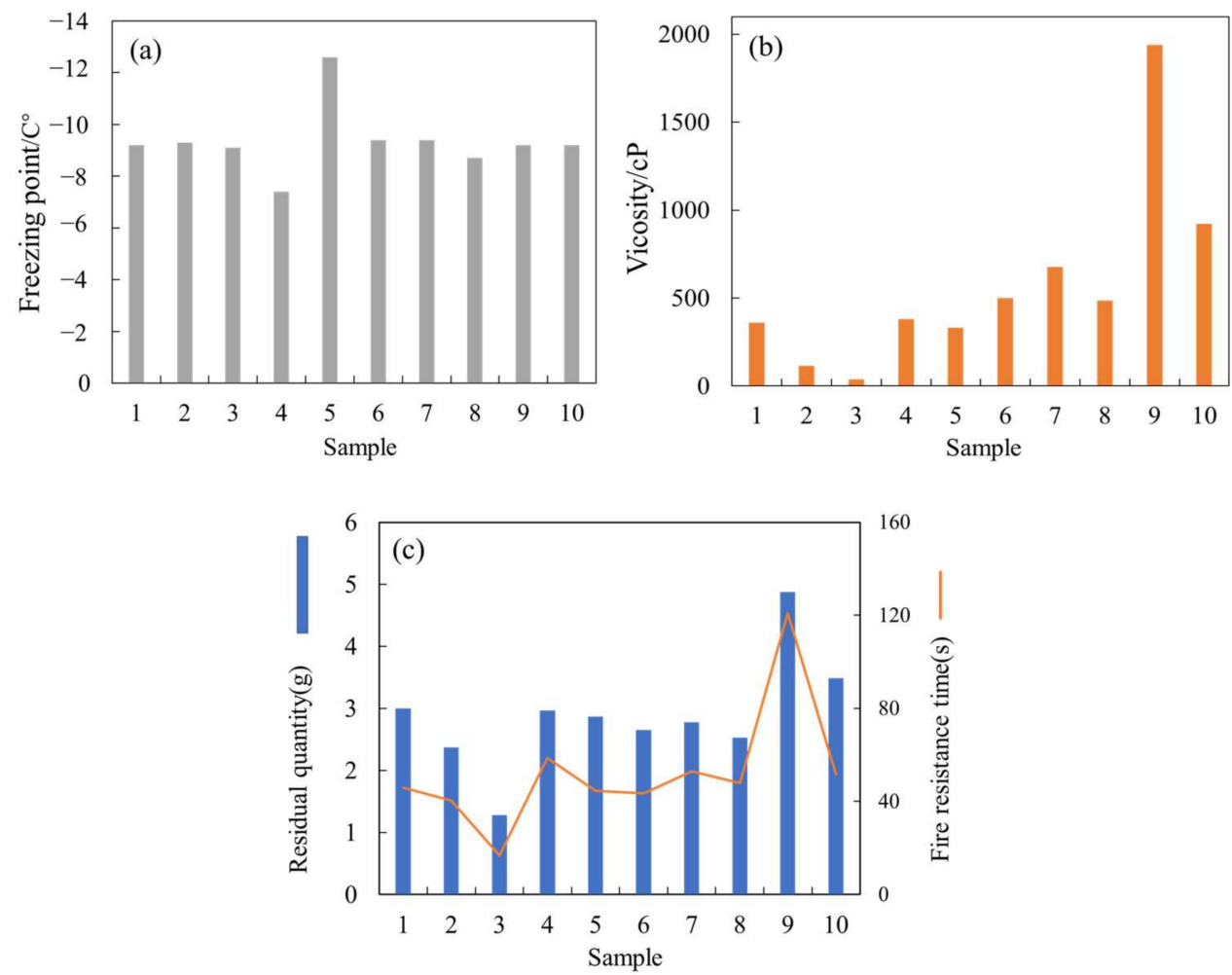

Figure 6. Comparison of the 10 samples of modified hydrogel extinguishant solutions: (a) freezing point; (b) viscosity; (c) adhesion mass and flame retardance time on wood strips. 


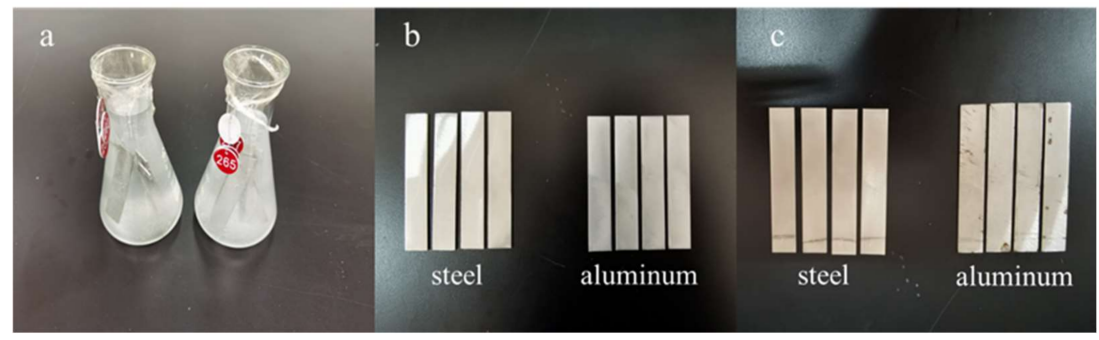

Figure 7. (a) Metal sheets being corroded in the hydrogel solution. (b) Metal sheets before corrosion and (c) after corrosion.

The specific results were presented in Table 4. The corrosion rates of solution No. 9 to the steel sheet and aluminum sheet were 1.8 and $0.9 \mathrm{mg} /\left(\mathrm{d} \cdot \mathrm{dm}^{2}\right)$, respectively, while those of extinguishant \#1 were 0.5 and $0.2 \mathrm{mg} /\left(\mathrm{d} \cdot \mathrm{dm}^{2}\right)$, respectively. The corrosion rate of the samples corresponding to both metal sheets was less than $15 \mathrm{mg} /\left(\mathrm{d} \cdot \mathrm{dm}^{2}\right)$, indicating that the corrosion performance of the modified hydrogel extinguishant satisfied the national standard (GB 15308) [31].

Table 4. The corrosion rate of the two tested samples on steel and aluminum sheets.

\begin{tabular}{ccc}
\hline \multirow{2}{*}{ Sample } & \multicolumn{2}{c}{ Corrosion Rate of Metal $\left(\mathbf{m g} /\left(\mathbf{d} \cdot \mathbf{d m}^{2}\right)\right)$} \\
\cline { 2 - 3 } & Steel Sheet & Aluminum Sheet \\
\hline Extinguishant \#1 solution $(0.5 \%)$ & 0.5 & 0.2 \\
No. 9 solution & 1.8 & 0.9 \\
\hline
\end{tabular}

Besides the corrosion, water was used as the matrix for the modified hydrogel extinguishants, and it is inevitable that the extinguishant will remain in the environment after use. Therefore, toxicity to aquatic organisms is an important index for evaluating environmental safety. In this study, the toxicity test standard referred to the national standard (GB 17835) [38]. For this, a standard diluted solution was first prepared, then aerated until the dissolved oxygen concentration reached the air saturation value and maintained a $\mathrm{pH}$ of $7.8 \pm 0.2$. Then, $12 \mathrm{~mL}$ of the recommended concentration of sample solution and $25 \mathrm{~mL}$ of standard dilution solution were contained to $2000 \mathrm{~mL}$. Subsequently, 10 healthy zebrafish were put into the solution at $21-25^{\circ} \mathrm{C}$ for $96 \mathrm{~h}$ to evaluate the toxicity of the hydrogel extinguishant. The number of fish in each beaker was recorded daily. The experiments involving zebrafish were approved by the Institutional Animal Care and Use Committee of the Research Center of Eco-Environmental Sciences, Chinese Academy of Sciences.

The toxicity results were shown in Figure 8. Overall, for both original and modified hydrogel solution, the zebrafishes had good vital signs, and no poisoning symptoms were observed during the experiment, such as loss of balance, respiratory rate, slow movement, or color change. All zebrafish of the two samples were alive after $96 \mathrm{~h}$. This mortality rate, being $\leq 50 \%$, demonstrates that the toxicity of the hydrogel solution \#1 (0.5\%) and No. 9 solution meets the national standard (GB17835) [38].

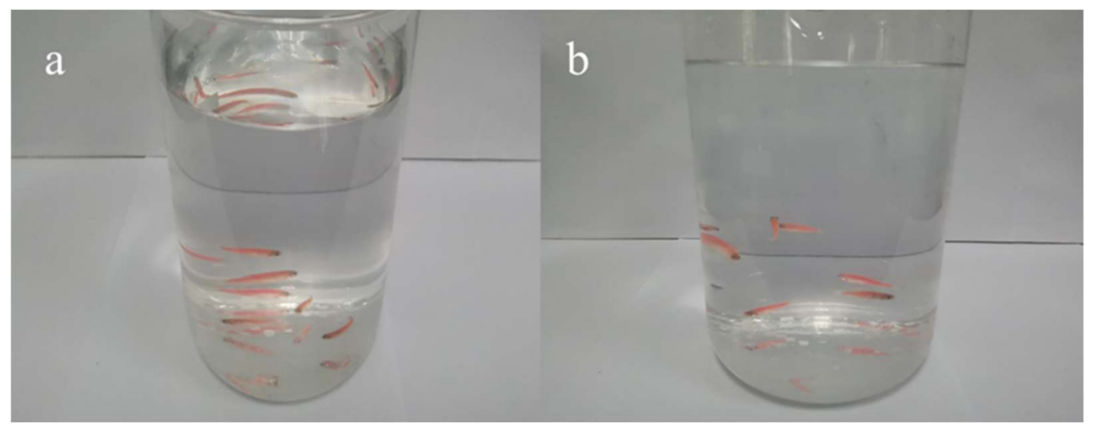

Figure 8. The state of zebrafish after $96 \mathrm{~h}$ in (a) hydrogel solution \#1 (0.5\%) and (b) No. 9 hydrogel solution. 


\section{Conclusions}

In this study, the modification of the freezing point for commercial hydrogel extinguishant and its effect on the comprehensive properties of forest fire rescue was systematically studied.

The freezing points of the original extinguishants \#1 and \#2 were similar, at -0.3 and $-0.5{ }^{\circ} \mathrm{C}$, respectively, indicating that neither of the solutions was suitable for the cold condition. By comparison, extinguishant \#1 featured a smaller particle size, a fast absorption rate, and better water dispersion performance. Thus, it was selected for further modification. The addition of antifreeze and other agents effectively changed the extinguishing performance. Ethylene glycol, as an antifreeze, exhibited the most obvious effect on viscosity improvement.

A series of orthogonal experiments further explored the effect of each additive on the comprehensive properties of the selected hydrogel extinguishant. The results showed that the viscosity, adhesion, and flame retardant performance of samples were improved with the increased concentration of extinguishant. Excessive ethylene glycol remarkably enhanced the frost resistance, yet it had an adverse effect on the fire-retarding performance. Among the three flame retardants, the combination of urea and ammonium bicarbonate had the most significant improvement on the adhesion and flame-retardant performance. In addition, both the viscosity and flame retardant time increased with the addition of xanthan gum. However, there was no significant change in the freezing point or adhesion ability. Of the 10 tested sample solutions, sample solution 9 exhibited the most outstanding comprehensive performance, which was significantly elevated compared to the original hydrogel extinguishant \#1. For sample solution 9, the freezing point and viscosity were $-9.2^{\circ} \mathrm{C}$ and $1938 \mathrm{cP}$, respectively. On the adhesion test, the mass retention rate was greater than $97 \%$. Notably, the flame retardance time was greater than $120 \mathrm{~s}$. Therefore, the corresponding optimal formula amounts of ultrapure water, hydrogel extinguishant powder \#1, ethylene glycol, urea, ammonium bicarbonate, and xanthan gum were determined to be $50 \mathrm{~mL}, 0.5 \mathrm{~g}, 5 \mathrm{~mL}, 0.08 \mathrm{~g}, 0.04 \mathrm{~g}$, and $0.12 \mathrm{~g}$, respectively. The corrosivity and biotoxicity of the modified No. 9 solution were consistent with the national standards. This indicates that the modified hydrogel extinguishant determined by this study is not only adaptable to lower ambient temperatures but is also more environmentally friendly.

Supplementary Materials: The following supporting information can be downloaded at: https: / /www.mdpi.com/article/10.3390/su14020752/s1, Table S1: The Characterization of the data of blank and 1\# hydrogel extinguishant.

Author Contributions: Conceptualization, Q.L. and M.H.; methodology, G.S. and J.M.; formal analysis, B.S. and J.D.; writing - original draft preparation, Z.H. and P.C. contributed equally to this paper; writing-review and editing, Z.H. and Q.L. All authors have read and agreed to the published version of the manuscript.

Funding: This research was funded by the Second Tibetan Plateau Scientific Expedition and Research (STEP) program (No.2019QZKK0682); Tianjin Fire Research Institute of M.E.M., (2019SJ16); National Natural Science Foundation of China (22006165, 21876193).

Institutional Review Board Statement: Not applicable.

Informed Consent Statement: Not applicable.

Data Availability Statement: Not applicable.

Conflicts of Interest: The authors declare no conflict of interest. 


\section{References}

1. Liodakis, S.; Antonopoulos, I.; Kakardakis, T. Evaluating the use of minerals as forest fire retardants. Fire Saf. J. 2010, 45, 98-105. [CrossRef]

2. Chiriacò, M.V.; Perugini, L.; Cimini, D.; D’Amato, E.; Valentini, R.; Bovio, G.; Corona, P.; Barbati, A. Comparison of approaches for reporting forest fire-related biomass loss and greenhouse gas emissions in southern Europe. Int. J. Wildland Fire 2013, 22, 730-738. [CrossRef]

3. Hanson, D.A.; Britney, E.M.; Earle, C.J.; Stewart, T.G. Adapting habitat equivalency analysis (HEA) to assess environmental loss and compensatory restoration following severe forest fires. For. Ecol. Manag. 2013, 294, 166-177. [CrossRef]

4. Morgan, P.; Heyerdahl, E.K.; Gibson, C.E. Multi-season climate synchronized forest fires throughout the 20th century, northern Rockies, USA. Ecology 2008, 89, 717-728. [CrossRef]

5. Zong, X.Z.; Tian, X.R.; Liu, J.L. A Fire Regime Zoning System for China. Front. For. Glob. Chang. 2021, 4, 11. [CrossRef]

6. Merino, L.; Caballero, F.; Martínez-de-Dios, J.R.; Maza, I.; Ollero, A. An unmanned aircraft system for automatic forest fire monitoring and measurement. J. Intell. Robot. Syst. 2011, 65, 533-548. [CrossRef]

7. Clark, N.A.; Martell, D.L. The use of aircraft tracking GPS data to develop models of the use of airtankers in forest fire management. INFOR Inf. Syst. Oper. Res. 2020, 57, 535-562. [CrossRef]

8. Volkov, R.S.; Kuznetsov, G.V.; Strizhak, P.A. Experimental study of the suppression of flaming combustion and thermal decomposition of model ground and crown forest fires. Combust. Explos. Shock Waves 2017, 53, 678-688. [CrossRef]

9. Andersson, B.; Blomqvist, P. Experimental study of thermal breakdown products from halogenated extinguishing agents. Fire Saf. J. 2011, 46, 104-115. [CrossRef]

10. Kloss, C.; Newland, M.J.; Oram, D.E.; Fraser, P.J.; Brenninkmeijer, C.A.M.; Rockmann, T.; Laube, J.C. Atmospheric abundances, trends and emissions of CFC-216ba, CFC-216ca and HCFC-225ca. Atmosphere 2014, 5, 420-434. [CrossRef]

11. Hu, A.Q.; Yuan, H.F.; Xue, G.; Song, C.F.; Li, X.Y.; Xie, J.C. Study on rapid quantitative analysis of the active ingredient in ABC extinguishing agent and type identification of extinguishing agent powders using near infrared spectroscopy. Spectrosc. Spect. Anal. 2012, 32, 2135-2138.

12. Linteris, G.T.; Babushok, V.I.; Pagliaro, J.L.; Burgess, D.R., Jr.; Manion, J.A.; Takahashi, F.; Katta, V.R.; Baker, P.T. Understanding overpressure in the FAA aerosol can test by C3H2F3Br (2-BTP). Combust Flame 2016, 167, 452-462. [CrossRef] [PubMed]

13. Zhang, T.; Du, Z.; Han, Z.; Liu, K. Performance evaluation of water mist with additives in suppressing cooking oil fires based on temperature analysis. Appl. Therm. Eng. 2016, 102, 1069-1074. [CrossRef]

14. Zhang, T.; Han, Z.; Du, Z.; Liu, K.; Zhang, Z.-L. Cooling characteristics of cooking oil using water mist during fire extinguishment. Appl. Therm. Eng. 2016, 107, 863-869. [CrossRef]

15. Banks, R.E.; Clarke, E.K.; Johnson, E.P.; Sharratt, P.N. Environmental Aspects of Fluorinated Materials: Part 31. Process Saf. Environ. 1998, 76, 229-238. [CrossRef]

16. Wang, P. Application of green surfactants developing environment friendly foam extinguishing agent. Fire Technol. 2014, 51, 503-511. [CrossRef]

17. Yu, X.; Jiang, N.; Miao, X.; Zong, R.; Sheng, Y.; Li, C.; Lu, S. Formation of stable aqueous foams on the ethanol layer: Synergistic stabilization of fluorosurfactant and polymers. Colloid Surf. A 2020, 591, 124545. [CrossRef]

18. Huang, Y.; Wencheng, Z.; Dai, X.; Zhao, Y. Study on water-based fire extinguishing agent formulations and properties. Procedia Eng. 2012, 45, 649-654. [CrossRef]

19. Mykhalichko, B.; Lavrenyuk, H.; Mykhalichko, O. New water-based fire extinguishant: Elaboration, bench-scale tests, and flame extinguishment efficiency determination by cupric chloride aqueous solutions. Fire Saf. J. 2019, 105, 188-195. [CrossRef]

20. Fan, Y.; Zhao, Y.; Hu, X.; Wu, M.; Xue, D. A novel fire prevention and control plastogel to inhibit spontaneous combustion of coal: Its characteristics and engineering applications. Fuel 2020, 263, 116693. [CrossRef]

21. Li, S.L.; Zhou, G.; Wang, Y.; Jing, B.; Qu, Y. Synthesis and characteristics of fire extinguishing gel with high water absorption for coal mines. Process Saf. Environ. 2019, 125, 207-218. [CrossRef]

22. Cheng, W.; Hu, X.; Xie, J.; Zhao, Y. An intelligent gel designed to control the spontaneous combustion of coal: Fire prevention and extinguishing properties. Fuel 2017, 210, 826-835. [CrossRef]

23. Yu, A.C.; Chen, H.; Chan, D.; Agmon, G.; Stapleton, L.M.; Sevit, A.M.; Tibbitt, M.W.; Acosta, J.D.; Zhang, T.; Franzia, P.W.; et al. Scalable manufacturing of biomimetic moldable hydrogels for industrial applications. Abstr. Pap. AME 2016, 113, 14255-14260. [CrossRef] [PubMed]

24. Qin, B.; Dou, G.; Wang, Y.; Xin, H.; Ma, L.; Wang, D. A superabsorbent hydrogel-ascorbic acid composite inhibitor for the suppression of coal oxidation. Fuel 2017, 190, 129-135. [CrossRef]

25. Lima, D.C.D.; Souza, A.P.D.; Keffer, J.F.; Bouvié, L.; Martim, C.C.; Ferneda, B.G. Effectiveness Of Water-Retaining Polymer as Fire Retardant In Indirect Use. Rev. Árvore 2020, 44, 1-11. [CrossRef]

26. Zhang, Y.; Qiu, Z.; Zhao, X.; Zhong, H.; Huang, W.; Mu, J. Experimental study on ultra-low temperature drilling fluid in Arctic permafrost. Polar Sci. 2021, 28, 100645. [CrossRef]

27. Kung, H.C.; Pabich, M.J.; Bell, K.M.; Jackson, E.; Franson, S.T. ESFR sprinkler protection of Class II commodity in cold storage warehouses using propylene glycol antifreeze agent. J. Fire Prot. Eng. 2007, 17, 145-157. [CrossRef]

28. Han, Z.; Gong, L.; Du, Z.; Duan, H. A novel environmental-friendly gel dry-water extinguishant containing additives with efficient combustion suppression efficiency. Fire Technol. 2020, 56, 2365-2385. [CrossRef] 
29. Han, Z.; Zhang, Y.; Du, Z.; Xu, F.; Li, S.; Zhang, J. New-type gel dry-water extinguishants and its effectiveness. J. Clean. Prod. 2017, 166, 590-600. [CrossRef]

30. Ma, X.X.; Wu, Y.Z.; Zhu, H.L. The fire-retardant properties of the melamine-modified urea-formaldehyde resins mixed with ammonium polyphosphate. J. Wood Sci. 2013, 59, 419-425. [CrossRef]

31. National Standard Full Text Disclosure System. Foam Exting Uishing a Gent: GB 15308-2006. Available online: http://www.gb6 88.cn/bzgk/gb/newGbInfo?hcno=00DC75835666D72E8B4AE464C9B8AE5F (accessed on 4 November 2021).

32. National Standard Full Text Disclosure System. GB 12441-2018 Decorative Fireproof Coating. Available online: http:/ / openstd. samr.gov.cn/bzgk/gb/newGbInfo?hcno=E4AD7F1E95F2878E32459BCF20878493 (accessed on 4 November 2021).

33. He, S.; Ruan, C.; Shi, Y.; Chen, G.; Ma, Y.; Dai, H.; Chen, X.; Yang, X. Insight to hydrophobic $\mathrm{SiO}_{2}$ encapsulated $\mathrm{SiO}_{2}$ gel: Preparation and application in fire extinguishing. J. Hazard. Mater. 2021, 405, 124216. [CrossRef] [PubMed]

34. Arvidson, M. Flammability of antifreeze agents for automatic sprinkler systems. J. Fire Prot. Eng. 2011, 21, 115-132. [CrossRef]

35. Zhang, W.; He, X.; Song, T.; Jiao, Q.; Yang, R. The influence of the phosphorus-based flame retardant on the flame retardancy of the epoxy resins. Polym. Degrad. Stab. 2014, 109, 209-217. [CrossRef]

36. Li, Y.; Li, B.; Dai, J.; Jia, H.; Gao, S. Synergistic effects of lanthanum oxide on a novel intumescent flame retardant polypropylene system. Polym. Degrad. Stab. 2008, 93, 9-16. [CrossRef]

37. Song, Z.; Ling, P.; Zang, H.; Li, L.; Wang, J.; Jin, Y.; Shao, H.; Zhu, X.; Liu, F.; Wang, F. Development, validation and influence factor analysis of a near-infrared method for the molecular weight determination of xanthan gum. Carbohydr. Polym. 2015, 115, 582-588. [CrossRef] [PubMed]

38. National Standard Full Text Disclosure System. Water Beased Extinguishing Agent: GB 17835-2008. Available online: http: //www.gb688.cn/bzgk/gb/newGbInfo?hcno=478DE68AE590E83D6E94111BBBE2B205 (accessed on 4 November 2021). 